\title{
Numerical and Experimental Study on Modular-Based Timber Structures
}

\author{
Sigurdur Ormarsson ${ }^{1 *}$, Johan Vessby ${ }^{2}$, Marie Johansson $^{3}$, and Le Kua ${ }^{4}$ \\ ${ }^{1}$ Professor, Building Technology, Linnaeus University, Sweden \\ ${ }^{2}$ Associate Professor, Building Technology, Karlstad University, Sweden \\ ${ }^{3}$ Senior Researcher, RISE, Technical Research Institute of Sweden \\ ${ }^{4}$ PhD student, Building Technology, Linnaeus University, Sweden \\ "Corresponding author's e-mail: sigurdur.ormarsson@lnu.se
}

\begin{abstract}
Building with prefabricated light-frame volume modules is a prevalent and innovative construction method for low and mid-rise timber buildings. Compared to traditionally site-built constructions this method is very advantageous due to its high prefabrication level and the fast on-site assembly of the modules. The focus of this project is to study and optimise the global shear stiffness of the volume modules and to secure a large enough shear and uplift stiffness of the mechanical (or friction based) connections between the modules. Some companies assume that the friction between the modules is sufficient to transfer the wind stabilization forces down through the entire building. Regarding structural safety, connection design is an important task that needs to be numerically studied and experimentally verified. The paper presents numerical and experimental results obtained from two ongoing research projects concerning modular-based timber buildings in Sweden. The final aim of this work is to develop an efficient three dimensional finite-element model to analyse both the global and detailed structural behaviour of these types of buildings. To study the overall shear stiffness of the volume modules, eight different test-modules are to be tested. The test results will be used to calibrate the numerical model.
\end{abstract}

\section{KEYWORDS}

Modular-based timber buildings; light-frame timber structures; FE-modelling; test-modules.

\section{INTRODUCTION}

The building of mid-rise buildings made from fully prefabricated volume modules in wood is an industry sector whose capacity in Sweden is increasing. Some manufacturers of single family homes are now planning to build buildings of 6-8 floors, see Figure 1. From many aspects, the building of modular-based timber buildings is a favourable production method. The production time, for example, is only about $20 \%$ of that needed for traditional site-built buildings. The volume modules are also manufactured in a well-controlled factory climate, where the wood material can retain its good quality. Environmentally, this way of building is a sustainable and environmentalfriendly construction method because of the efficient fabrication, transportation and installation processes, and the low material waste and good recycling possibility. In the future, this building technology has the potential to significantly increase the use of wood as a construction material and thus contribute towards the UN's Sustainable Development Goals (SDGs) set out in Agenda 2030 . 


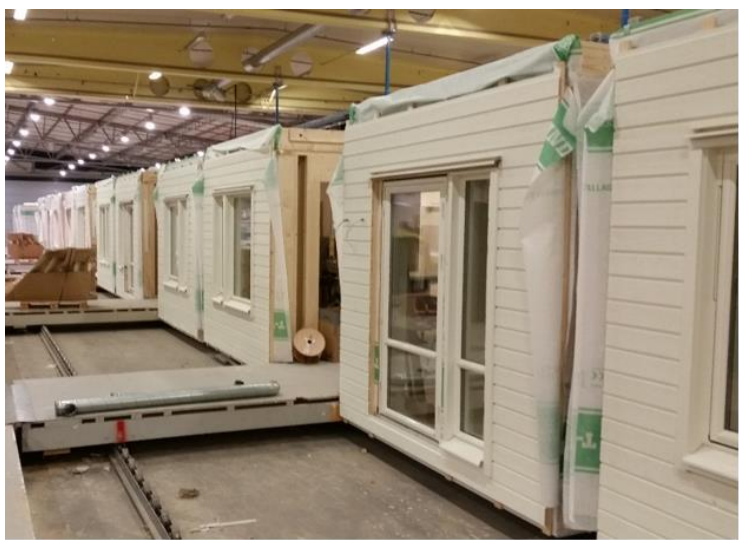

(a)

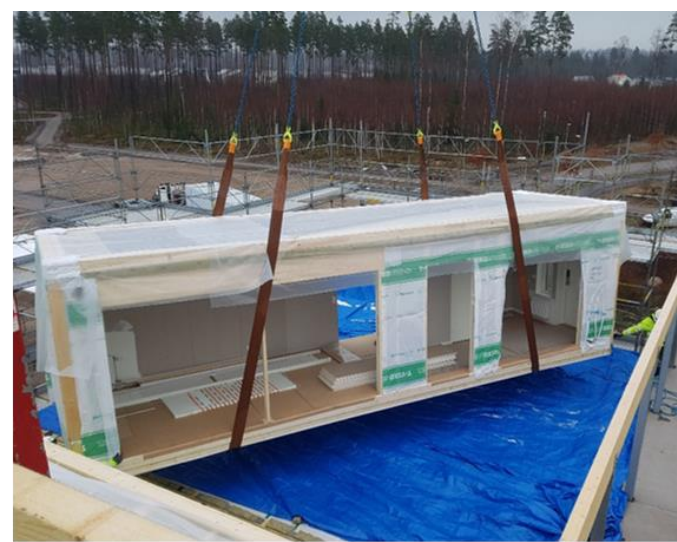

(b)

Figure 1. Production of mid-rise modular-based timber building, $(a)$ production of the volume modules in a factory climate, $(b)$ assembly of volume modules on the construction site.

The construction of mid-rise timber buildings (glulam framed, light-frame shear walls or CLT based) up to 6-8 floors is well-established today. High timber buildings are sensitive to overturn, overall bending/shear deformations (earthquake loads), and vibrations caused by strong wind loading. Global wind stabilization of mid-rise timber buildings using shear walls has previously been studied by (Källsner and Girhammar 2009, Vessby 2011). The limits for accelerations in timber buildings are provided in, for example (EN 1991-1-4: 2005, ISO 10137: 2007, Johansson et al. 2015). Experimental work about the dynamic structural behaviour of modular-based timber buildings has been reported, e.g. (Li et al. 2012, Jørstad 2013, Jørstad and Malo 2012). Numerical works regarding finite element simulations of individual shear wall elements, individual volume modules and some modular-based timber buildings are e.g. (Ormarsson and Johansson 2018, Rinaldin et al. 2016, He et al. 2001).

This work presents the results from ongoing research projects concerning the numerical and experimental study of modular-based timber buildings. The main aim of the work is to develop an efficient three-dimensional finite-element model to study the global structural behaviour of these types of buildings when exposed to mechanical and moisture related loadings. The work will be based on experimentally obtained data for different connection solutions and validated by fullscale tests for different structural elements, such as shear walls and test-modules.

\section{MODELLING}

The load bearing structures of light-frame modular-based timber buildings consist of numerous slender timber elements (studs, rails, timber boards, noggin pieces, door and window sills, solid timber beams, glulam beams, plasterboards and different types of fibre boards) that are connected together by a huge number of mechanical nail, staples or screw joints. When simulating large and complex structures the numerical models easily become too large and computationally heavy. To deal with this problem for this type of timber structure, various types of effective structural elements (springs, beams and shells in 3D space) have been used, see (Ormarsson and Johansson 2018) for the model description. A major challenge here is to model the different types of mechanical connections properly and efficiently. To facilitate the creation and assembly of these timber components, a parameterized model was created in which the house geometry is defined by relatively few input parameters. 


\section{Simulation of individual timber walls}

Wall elements in volume modules act as typical shear walls in timber buildings resisting wind loads. In the Master thesis by (Kormendy and Muwaili 2018) the wall model in (Ormarsson and Johansson 2018) was developed further regarding the simulation and graphical illustration of the fastener forces. Figure 2 shows the out-of-plane bending and elastic fastener force distribution in a timber wall exposed to in-plane shear loading. The figure also shows visible slippage deformation between the sheathing boards and that the largest fastener forces occur close to the corners of the door opening. The forces are also large close to the corners of the plasterboards.

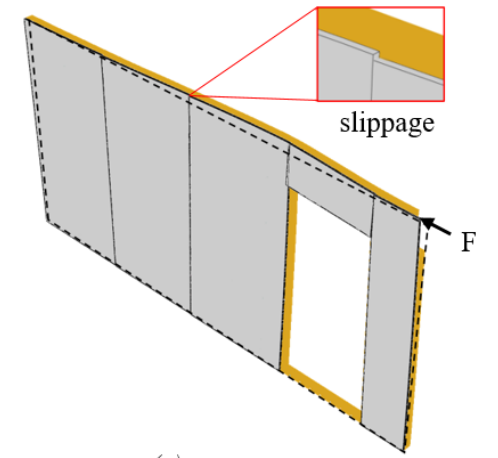

(a)

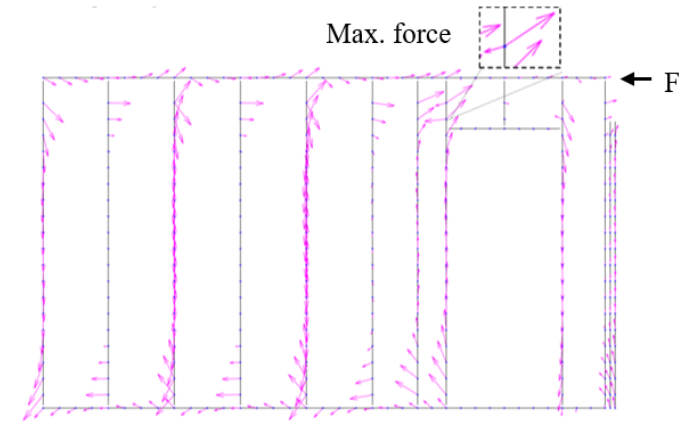

(b)

Figure 2. Simulation of a light-frame shear wall by (Kormendy and Muwaili 2018), (a) out-ofplane deformation and close-up on a slippage deformation between two plasterboards, $(b)$ elastic fastener force distribution in the wall.

\section{Modelling of a two-module structure}

To simulate the structural behaviour of volume modules, the parametrized FE-model presented in (Ormarsson and Johansson 2018) was further developed by (Augustino and Antwi-Afari 2018) to analyse an asymmetric two-volume structure made of walls with different openings. For structures with two or more module elements the connections between the modules are critical. The connection in this work was modelled with different spring elements representing both friction and mechanical fasteners.
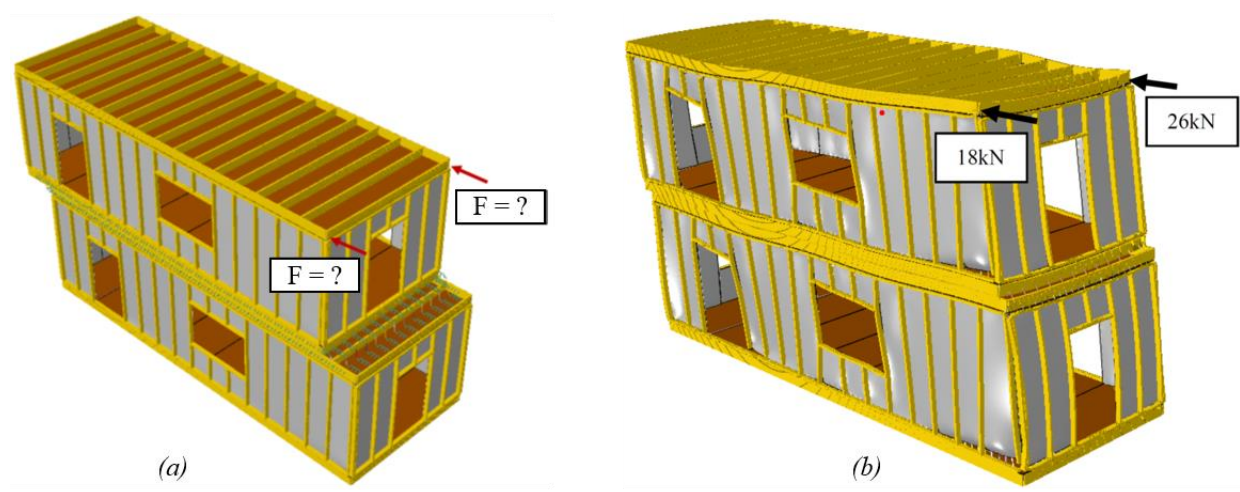

Figure 3. Simulated deformations of two-module structures caused by a prescribed horizontal displacement of $10 \mathrm{~mm}$ (note, all deformations are sized by a factor of 100) (Augustino and Antwi-Afari 2018), (a) a structure with small friction properties between the modules, (b) a structure with relatively stiff mechanical joints between the modules. 
The two-module structure shown in Figure 3 is exposed to a prescribed horizontal displacement of $10 \mathrm{~mm}$ at the top right corner of the structure. The results show how the size and locations of the openings greatly influence the global shear stiffness of the structure and the importance of stiff mechanical connections between the volume elements to make the structure work as a unit. Of note, the different slip deformations between the modules when the deformations have been sized by factor of 100 . Figure $3(b)$ indicates an uplift deformation at the right bottom corners of the bottom volume.

\section{Ongoing modelling work}

Within these research projects, the model will be further developed to analyse mid-rise modularbased timber buildings with more correct and more detailed geometries. Great focus will be placed on parametrized modelling to improve the flexibility of geometrical descriptions, material properties, loads, boundary conditions, etc. To study the connection behaviours further, adaptive modelling will also be performed for the most critical connections in the structure. Figure 4 shows preliminary modelling results of a deformed five story tower and the test-module studied.
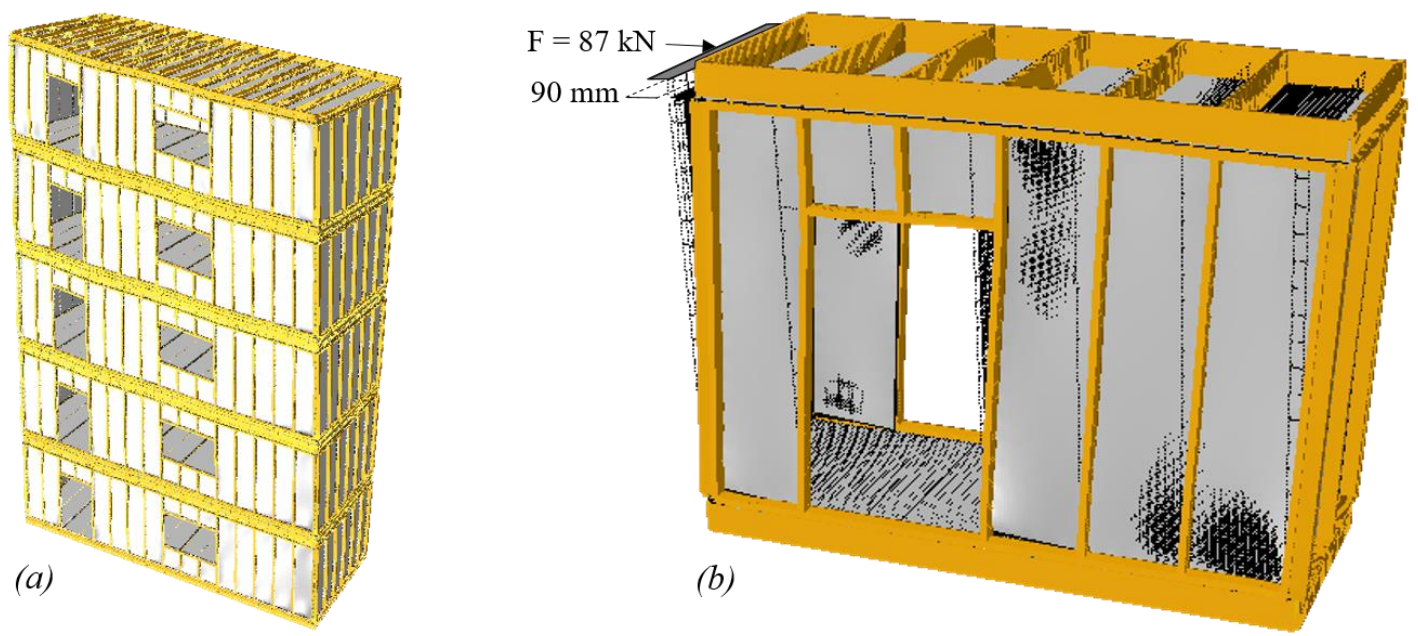

Figure 4. Simulated deformations of a five story modular-based timber tower and the testmodule studied, $(a)$ structure loaded in biaxial bending, $(b)$ structure forced to horizontal displacement of $90 \mathrm{~mm}$ at the left top side of the module (deformations sized by factor of 2 ).

The overall bending of the five story tower seems to generate significant uplift forces, which need to be carefully anchored to the some heavy supports. To validate the final FE-model, full-scale tests on individual volume modules and possibly two-module structures need be performed. The following test results were used to roughly calibrate the stiffness parameters of the different mechanical connections and thus attain reasonable values of the reaction force caused by the prescribed horizontal displacement at the left top side of the test-module, see Figure 4(b).

\section{TESTING OF SMALL VOLUME MODULES}

Based on results from the pre-study presented here, full-scale tests are planned in this research project. The pre-study deals with the testing of eight test-modules manufactured by the four companies involved in the project. All connection details and dimensions are the same except for the lengths of all walls and the floor elements, which are significantly reduced in the test-modules. Each company produces two types of modules, as shown in Figure 5. 


\section{Geometry and material data}

The overall dimensions of the modules are $1 \times \mathrm{w} \times \mathrm{h}=3.6 \times 1.2 \times 3.0 \mathrm{~m}$. The test-modules are produced with a timber frame and double layers of plasterboards with 13 and $15 \mathrm{~mm}$ thicknesses respectively screwed to the frame. The cross section dimensions of the studs/rails in module type 1 are $45 \times 95 \mathrm{~mm}$ in the long walls and $45 \times 220 \mathrm{~mm}$ in the short walls. For the module type 2 the dimensions are the opposite; hence, the studs and rails are greater for the longer walls. The cross section dimensions of the floor beams are $45 \times 220 \mathrm{~mm}$ and the thickness of the particle boards is $22 \mathrm{~mm}$. All four prefabricated wall elements are interconnected at their ends with mechanical screws. However, the flooring is fastened to the walls with glue and mechanical fasteners. The wall rails are fastened by glue to the chipboard sheathing together with screws through the rail and the chipboard down to the beams in the flooring.

\section{Experimental setup}

To test the modules, a new testing facility was designed and built in the project. Figure 5 shows 3D-drawings of the testing facility and experimental setups for the two types of modules.
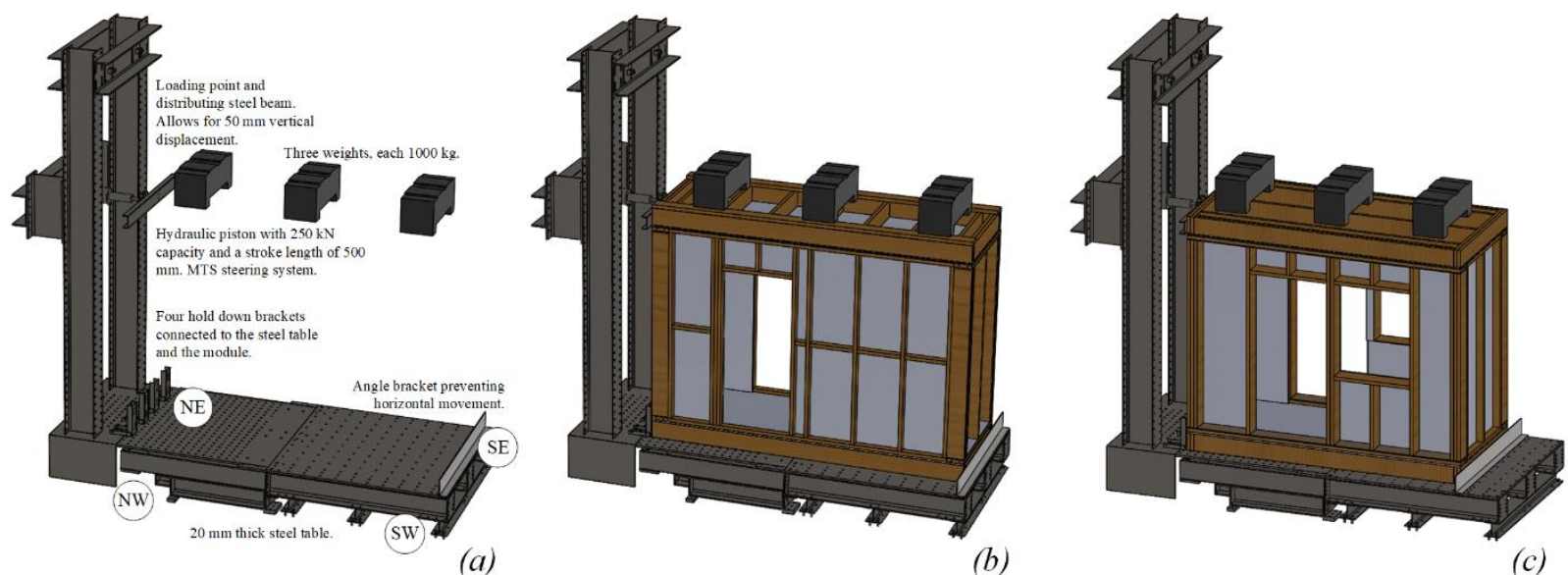

Figure 5. Experimental setup for the two types of test-modules studied, (a) facility used, $(b)$ a module type 1 oriented (and loaded) in the length direction of the full-sized module, $(c)$ module type 2 oriented perpendicular to the length direction of the full-sized module.

To study the global structural shear behaviour of the entire volume, the module is loaded with a horizontal displacement transferred to the roof element as a line load by means of a steel UPE beam, shown in Figure 5 (top left side of the module). At the lower right end, the floor element is fixed against horizontal displacement, and to avoid module uplift it is anchored down to the steel fixture at the lower left end through four brackets attached to the steel table and screwed to the flooring element. To represent a permanent load from the upper floors a dead weight of 3,000 kg is placed on the top of the roof elements, see Figure 5. To avoid sidewise deformations and lateral instability problems, all the modules were built as symmetric as possible. The short wall of the module, where the loading point is located, is referred to as the north side.

\section{Experimental procedure}

The modules were tested in typical indoor climate conditions using displacement controlled loading with a rate of $15 \mathrm{~mm} / \mathrm{min}$ up to a maximal stroke length of $150 \mathrm{~mm}$. The global shear deformations, stiffness and the load carrying capacity of the volume element were measured by 
means of potentiometers placed at various locations of the module and a load cell in the front of the loading piston. All visible cracks and other damage modes were photographed and documented. Digital image correlation, through a DIC system, was performed during the testing and local measurements of some selected slip and opening deformations in the mechanical and glued joints were performed as well. Figure $6(a)$ shows a photo of the test setup. The dark markers on the surface of the wall are used for the DIC system, to follow the global coordinates in 3D during the test. Twenty one displacement gauges (potentiometers) were used to measure the global and relative displacements at certain locations. In each corner of the module the potentiometers are placed to measure the slip and the opening deformations of the joints between the timber walls and the floor elements.

\section{Experimental results}

The global load-displacement curve for the test is shown in Figure 6(c). The result shows the module as a structure to be rather stiff, with a linear load-displacement behaviour up to a load level of $60 \mathrm{kN}$ followed by increased nonlinearity up to the maximum load of $92.0 \mathrm{kN}$.

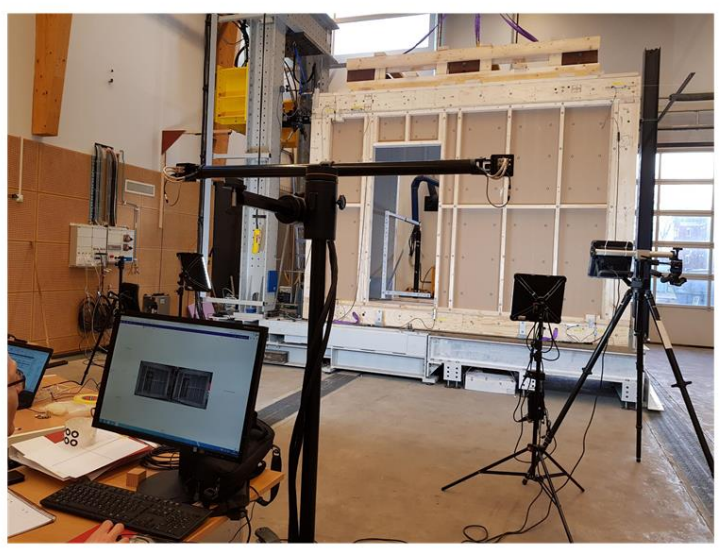

(a)

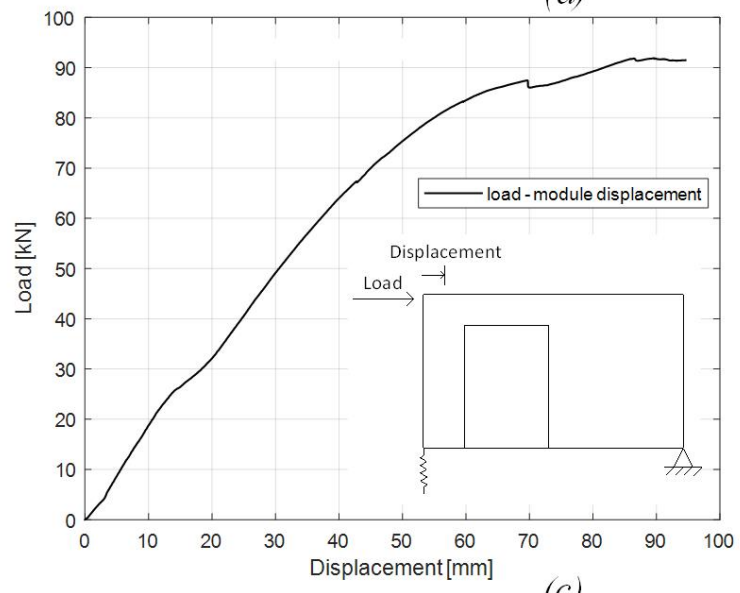

(c)

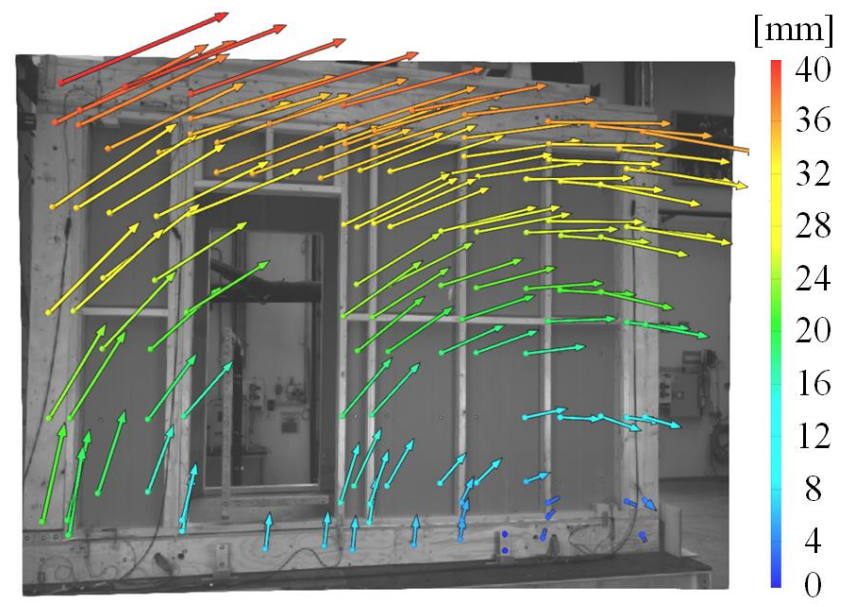

(b)

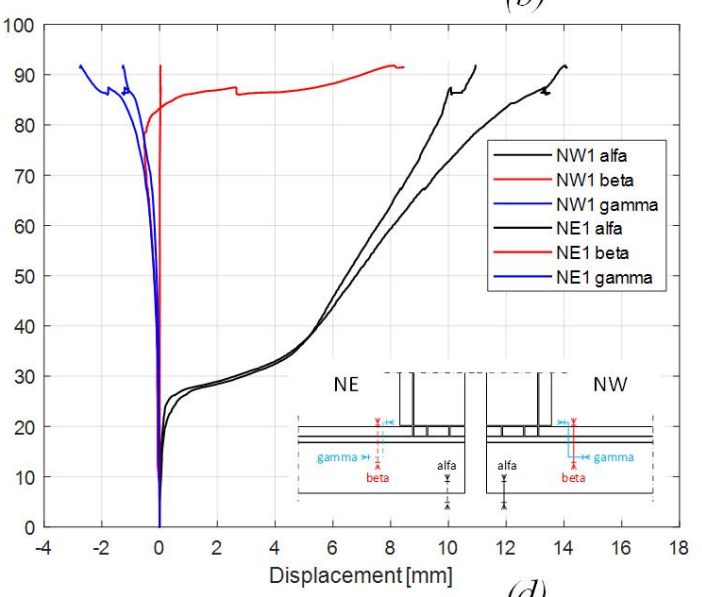

(d)

Figure 6. Experimental setup and selected results showing, $(a)$ the test setup with the DIC system and the potentiometers for local measurements, $(b)$ the displacement vectors from the DIC system, (c) the global load-displacement curve for the test-volume, $(d)$ the local load-slip curves for the joints between the wall and the floor element and the substrate (lower NW and NE side). 
From the experiment, Figure $6(d)$ shows load-displacement curves from six potentiometers, three placed at the northwest bottom corner and three placed in the northeast bottom corner. The results indicate that for loads greater than $25 \mathrm{kN}$ the floor element lifts from the steel table. This uplift is held back by the mechanical connection between the four steel brackets and the floor element. For loads greater than $80 \mathrm{kN}$, there is a successively increasing slip between the bottom rail and the floor element in the horizontal direction at both sides and in the vertical direction at the northwest side of the module. Finally, Figure $6(b)$ shows displacement vectors obtained from the DIC system after the prescribed horizontal displacement of approximately $45 \mathrm{~mm}$. The direction of the arrows indicate clearly the combined shear and uplift deformation of the volume module. The maximum load of $92 \mathrm{kN}$ occurred after approximately $90 \mathrm{~mm}$ of horizontal displacement of the roof element. Some photos of the most visible damage after unloading of the module are shown in Figure. 7.
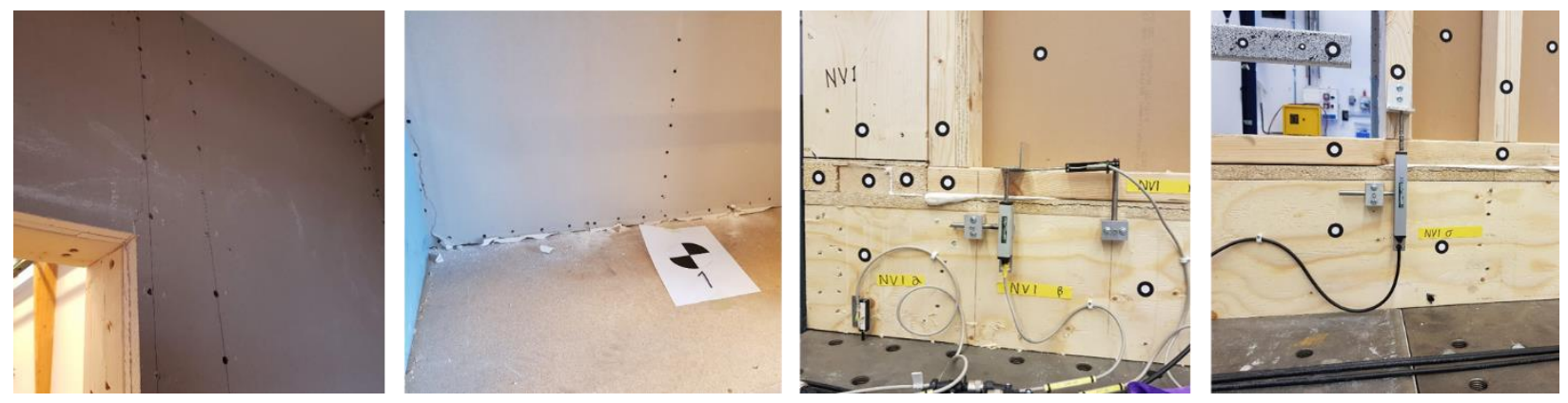

Figure 7. Most visible damage in the gypsum boards and the mechanical connections after unloading of the module.

The most visible cracks of the plasterboards were slightly skewed upwards from the upper north corners of the door openings. The plasterboards were also severely damaged in compression in the bottom end furthest from the load equipment. The only visible fractures in the connections between the wall and floor element were the longitudinal cracks inside the particleboard below the glued joint between the bottom sill and the floor element. These cracks are located close to the northern bottom corner and the door openings, where significant uplift force occurred.

\section{CONCLUSION}

Based on the computational time of the studied structures, it is concluded that creating an efficient and reasonable three dimensional finite element model to analyse an entire mid-rise modular-based timber building within a reasonable computational time is possible. The model needs to also be fully parameterized to increase its flexibility to analyse different types of modular-based buildings. Based on reasonable input data the simulation model gives valuable information regarding the global structural behavior of the 3D structure as well as information of fastener forces acting in all mechanical connections. These forces can be directly implemented in the design equations used for the individual shear connections.

The main experimental finding from this study (module 1) is that the module became both stiffer and stronger than expected. The mechanical connections worked very well and the overall loaddisplacement relationship showed linear variation up to approximately two third of the maximum load. The different test results were used to validate a preliminary model of the test-module. The experimentally-based stiffness values found for the mechanical connections differ markedly from 
the values used previously. This clearly shows the importance of the connection stiffness on the global module behavior. Finally, extensive experimental studies need to be performed on both connection and full-scale levels.

\section{ACKNOWLEDGEMENTS}

This work is financially supported by The Knowledge Foundation, Södra Foundation for Research and SHS Smart Housing Småland within three national research projects at LNU. The wood construction companies participating in the projects are SÖDRA, OBOS, Moelven byggmodul, Derome Plusshus and VIDA Buildings. The financial and technical support provided by the research foundations and the companies is gratefully acknowledged.

\section{REFERENCES}

Augustino, D.S., and Antwi-Afari, B.A., (2018). "Parameterized Modelling of Global Structural Behaviour of Modular Based Two-Storey Timber Structure." Master Thesis, Linnaeus University, Department of Building Technology, Växjö, Sweden.

EN 1991-1-4: (2005). "Eurocode 1: Actions on structures - Part 1-4: General actions - Wind actions".

He, M., Lam, F., and Foschi, R. O. (2001). "Modeling Three-Dimensional Timber Light-Frame Buildings." Journal of Structural Engineering, 127(8), 901-913.

ISO 10137:2007, (2007). "Bases for design of structures - Serviceability of buildings and walkways against vibration".

Johansson, M., Linderholt, A., Bolmsvik, Å., Jarnerö, K., and Olsson, J., (2015). "Building higher with light-weight timber structures: the effect of wind induced vibrations." In proceedings of the Internoise conference, San Francisco, USA, 9 -12 August.

Jørstad, A., (2013). "Dynamic Testing and Numerical Modelling of Residential Building Modules." Master Thesis, NTNU, Norwegian University of Science and Technology, Department of Structural Engineering, Trondheim, Norway.

Jørstad, A., and Malo, K.A., (2012). "Measurements of structural damping in prefabricated residential modules fabricated by kodumaja, estonia." Technical report, NTNU, Norwegian University of Science and Technology, Department of Structural Engineering, Trondheim, Norway.

Kormendy, I., and Muwaili, M., (2018). "Timber Shear Wall Analysis - Parameterized Finite Element Modelling," Master Thesis, Linnaeus University, Department of Building Technology, Växjö, Sweden.

Källsner, B., and Girhammar, U.A., (2009). "Analysis of fully anchored light-frame timber shear walls - elastic model." RELEM, Material and Structures, 42, 301-320.

Li, M., Lam, F., Foschi, R. O., Nakajima, S., and Nakagawa, T. (2012). "Seismic performance of post and beam timber buildings I: model development and verification." J Wood Sci, 58, 2030.

Ormarsson, S., and Johansson, M., (2018). "Finite element simulation of global structural behaviour of multifamily timber buildings using prefabricated volume modules." In WCTE 2018 World Conference on Timber Engineering. August 20-23, Seoul, Rep. of Korea.

Rinaldin, G., and Fragiacomo M. (2016). "Non-linear simulation of shaking-table tests on 3- and 7-storey X-Lam timber buildings.” Engineering Structures, 113, 133-148.

Vessby, J., (2011). "Analysis of Shear Walls for Multi-Storey Timber Buildings." PhD Thesis. Linnaeus University, Department of Building Technology, Växjö, Sweden. 